\title{
ESPECIALIZACIÓN EN GINECOLOGÍA ONCOLÓGICA
}

\author{
Edmundo Mora Padilla MD*
}

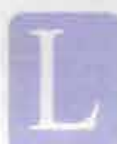

a necesidad de implementar esta especialidad comenzó en el mundo hace ya por lo menos 80 años. Dentro de la disciplina ginecológica se comenzaron a individualizar áreas de conocimientos especiales que eran importantes para el cuidado de la salud femenina y que no se podían obtener dentro del programa habitual de residencia en Ginecología y Obstetricia.

En nuestro país la idea de una institución especializada en cáncer fue concebida por el profesor francés Claude Regaud en la conferencia dictada en el Teatro Colón “Cómo organizar la detención del cáncer" realizada el 15 de noviembre de 1928. Entusiasta con esta presentación, el entonces ministro de Instrucción Pública doctor José Vicente Huertas, presentó anteel Congreso de la República de Colombia la propuesta de creación del Instituto Nacional de Radium, como parte de la Universidad Nacional. El primero de enero de 1951 se convirtió en Instituto Nacional de Cancerología, entidad especializada del orden nacional adscrito al Ministerio de Salud.

En el Hospital de San José se dio inicio al área de ginecología oncológica en 1980. Los especialistas que apoyaban el servicio en nuestro hospital eran los mismos que pertenecían al Instituto Nacional de Cancerología. Así, con el esfuerzo mancomunadode estos médicos junto con el de las directivas de la Sociedad de Cirugía de Bogotá y del Hospital de San José, se organizó el servicio en 1996. En la actualidad cuenta con un gran volumen de pacientes, tanto en la consulta externa como en cirugía oncológica de mayor complejidad, logrando con el paso de los años el reconocimiento a nivel nacional.

Ginecólogo oncólogo, Profesor Titular, Director del Programa, Fundación Universitaria de Ciencias de la Salud. Hospital de San José. Bogotá D.C. Colombia.

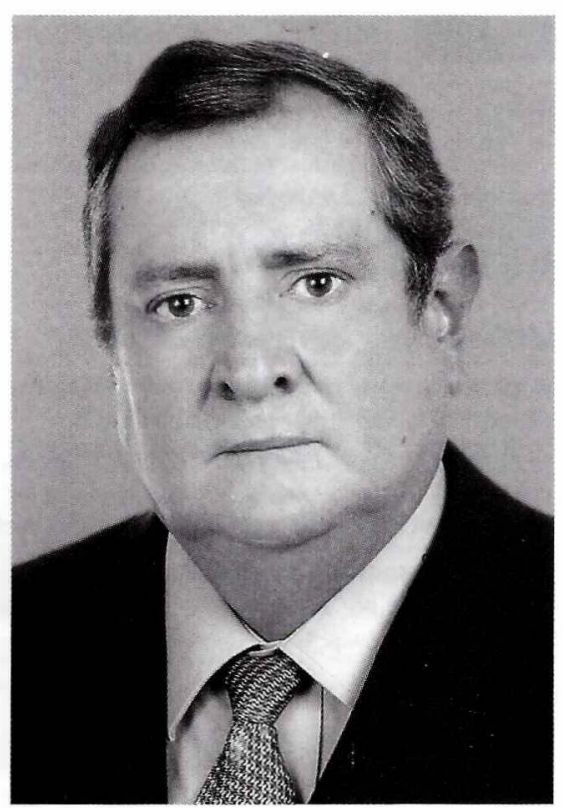

Uno de los adelantos más notables en todo el mundo en la asistencia sanitaria de la mujer ha sido la prevención primaria y secundaria del carcinoma cervico-uterino. A pesar de ello, en nuestropaís el cáncer ginecológico tiene un elevado índice de morbimortalidad, alcanzando una incidencia muy preocupante. Es así como el cáncer de cérvix afecta a 35 de cada 100.000 mujeres y sitúa a Colombia en el quinto lugar en Suramérica luego de Haití, Bolivia, Perú y Nicaragua.

Sumado a lo anterior, en nuestro medio en la actualidad hay menos de un centenar de especialistas en esta área, lo cual constituye un estándar muy bajo, sin contar que más del 50\% de ellos se concentra en la ciudad capital, quedando al descubierto la población más vulnerable como es la de los estratos socioeconómicos bajos, distribuidos en su gran mayoría en las regiones apartadas 